\title{
Histological and immunohistochemical study of the gall bladder lesion in primary sclerosing cholangitis
}

\author{
G P Jeffrey, W D Reed, S Carrello, K B Shilkin
}

\begin{abstract}
The histological features and type of mononuclear cell infiltrate in gall bladders from six patients with primary sclerosing cholangitis were studied using routine staining techniques and immunohistochemistry. Control studies were performed using the gall bladders from six patients (age and sex matched) with chronic cholecystitis and four with primary biliary cirrhosis. A range of histological abnormalities was present in gall bladders from patients with primary sclerosing cholangitis including a mild to moderate degree of epithelial hyperplasia, pseudogland formation, and mononuclear cell infiltrate of the epithelium; moderate to severe chronic inflammatory cell infiltrate and fibrosis affecting the superficial and deep layers of the gall bladder wall; and minimal smooth muscle hypertrophy. These abnormalities were nonspecific and were also present in gall bladders from patients with chronic cholecystitis and primary biliary cirrhosis. Vasculitis and granulomas were not present in the patients with primary sclerosing cholangitis. Immunohistochemistry showed that the superficial and deep mononuclear cell infiltrate in primary sclerosing cholangitis gall bladders was composed predominantly of lymphocytes, in contrast to chronic cholecystitis where macrophages were found in similar or greater numbers. Moreover, $T$ lymphocytes (activated and resting) were present throughout the lymphocytic infiltrate and were apposed to the base and interdigitated between the biliary epithelial cells in significantly greater numbers than in chronic cholecystitis gall bladders. B lymphocytes were present only in lymphoid follicles. Comparative studies using liver biopsy specimens from three of the primary sclerosing cholangitis patients showed a similar $T$ lymphocyte portal tract infiltrate. We conclude that a number of non-specific chronic inflammatory histological abnormalities were present in primary sclerosing cholangitis gall bladders. Immunohistochemistry found other features that were present in this disease - a predominantly lymphocytic mononuclear cell infiltrate of the superficial and deep layers of the gall bladder wall and the presence of $T$ lymphocytes that infiltrated the biliary epithelial cells. These findings support the hypothesis that aberrant cell mediated immune mechanisms may play a role in the pathogenesis of both the intrahepatic and extrahepatic lesions in primary sclerosing cholangitis.
\end{abstract}

Primary sclerosing cholangitis is an important and increasingly recognised cause of the vanish- ing bile duct syndrome.' The characteristic cholangiographic features of multiple beads and strictures are a result of chronic inflammation and obliterative fibrosis that affects the whole biliary tree. ${ }^{2}$ Although the aetiology remains unknown, evidence suggests that humoral and cell mediated immunological abnormalities play a role in the pathogenesis of this disorder. Studies have reported the presence of hyperglobulinaemia and circulating organ non-specific autoantibodies, ${ }^{23}$ high values of circulating immune complexes in blood and bile, ${ }^{45}$ activation of the complement pathway (C3), ${ }^{6}$ and impaired Fc receptor mediated systemic clearance of circulating immune complexes. ${ }^{7}$ Cell mediated immunological abnormalities found in this disorder include peripheral blood lymphocytes that are sensitised to bile antigens, ${ }^{8} \mathrm{~T}$ lymphocyte infiltrate of portal tracts and a deficiency in circulating suppressor/cytotoxic T cells, ${ }^{9}$ and defective suppressor $\mathrm{T}$ cell function. ${ }^{10}$ In addition, aberrant expression of HLA-DR antigens, which are a prerequisite for antigen presentation and initiation of the immune response, have been shown on biliary epithelium in primary sclerosing cholangitis. ${ }^{11}$

The pathognomonic lesion of intrahepatic primary sclerosing cholangitis is reported to be inflammatory and fibrous obliteration of the interlobular, septal, and segmental ducts with the development of saccular and tubular biliary dilatations. ${ }^{12}$ However, the extrahepatic biliary lesion in this disease, which may occur in isolation, ${ }^{2}$ has been less well characterised. The aim of this study was to review the histology and determine the nature of the inflammatory cell infiltrate within the extrahepatic biliary lesion in primary sclerosing cholangitis.

\section{Methods}

\section{PATIENTS}

The case records of 26 patients with primary sclerosing cholangitis attending the Sir Charles Gairdner Hospital Gastroenterology/Liver Unit were reviewed. The diagnosis was based on the presence of typical cholangiographic features in patients who had not undergone previous bile duct surgery, other than simple cholecystectomy. ${ }^{13}$ Fourteen of these patients $(58 \%)$ had associated ulcerative colitis. Cholecystectomy had been performed in eight and the gall bladder specimens from six of these patients were available for study. The clinical characteristics of these patients are shown in Table I. Only one patient had ulcerative colitis. None of the remaining five had symptoms suggestive of ulcerative colitis and fibreoptic colonoscopy or sigmoidoscopy with colonic biopsy specimen 
TABLE I Clinical, biochemical, and histological data of patients with primary sclerosing cholangitis at the time of cholecystectomy

\begin{tabular}{|c|c|c|c|c|c|c|}
\hline & \multicolumn{6}{|l|}{ Patient No } \\
\hline & 1 & 2 & 3 & 4 & 5 & 6 \\
\hline Sex & $M$ & $M$ & $\mathrm{~F}$ & $M$ & $\mathbf{F}$ & $\mathbf{F}$ \\
\hline Age (years) & 70 & 72 & 44 & 49 & 64 & 44 \\
\hline $\begin{array}{l}\text { Indication for } \\
\text { cholecystectomy }\end{array}$ & $\begin{array}{l}\text { Possible chole- } \\
\text { docholithiasis }\end{array}$ & $\begin{array}{l}\text { Recurrent } \\
\text { pancreatitis }\end{array}$ & $\begin{array}{l}\text { Recurrent } \\
\text { pancreatitis }\end{array}$ & $\begin{array}{l}\text { Possible chole- } \\
\text { docholithiasis }\end{array}$ & $\begin{array}{l}\text { Possible chole- } \\
\text { docholithiasis }\end{array}$ & $\begin{array}{l}\text { Recurrent } \\
\text { pancreatitis }\end{array}$ \\
\hline ERCP changes & $\mathrm{IH}+\mathrm{EH}$ & IH & $\mathrm{IH}+\mathrm{EH}$ & $\mathrm{IH}$ & IH & $\mathrm{IH}+\mathrm{EH}$ \\
\hline Ulcerative colitis & No & No & No & No & No & Yes \\
\hline Bilirubin $(\mu \mathrm{mol} / \mathrm{l})^{\star}$ & 14 & 13 & 24 & 156 & 8 & 7 \\
\hline $\mathrm{ALP}(\mathrm{N} 100-350 \mathrm{U} / \mathrm{l})$ & 716 & 489 & 169 & 1273 & 920 & 1179 \\
\hline Liver biopsy staget & ND & ND & I & II & III & ND \\
\hline Cholelithiasis & No & No & Yes & No & No & No \\
\hline
\end{tabular}

$\mathrm{ERCP}=$ endoscopic retrograde cholangiopancreatographic; $\mathrm{IH}=$ intrahepatic; $\mathrm{EH}=$ extrahepatic; $\mathrm{ALP}=$ serum alkaline phosphatase; $\mathrm{ND}=$ not done.

Normal range 0-17 $\mu \mathrm{mol} / 1$.

†Staged according to LaRusso et al. ${ }^{13}$

was normal in four of these. One patient refused to have this procedure performed. Gall bladder specimens from six patients (age and sex matched) with chronic cholecystitis and from four with primary biliary cirrhosis were obtained as controls. Liver biopsy specimens from three primary sclerosing cholangitis and all four primary biliary cirrhosis patients were available for comparative studies. All specimens had been fixed in formalin and embedded in paraffin wax.

\section{IMMUNOHISTOCHEMISTRY}

The formalin fixed, paraffin embedded gall bladder and liver biopsy specimens were sectioned $(5 \mu \mathrm{m})$, dewaxed, and blocked with $3 \%$ $\mathrm{H}_{2} \mathrm{O}_{2}$ in Tris buffered saline (TBS) $(20 \mathrm{mM}$ Tris, $500 \mathrm{mM} \mathrm{NaCl}, \mathrm{pH} \mathrm{7.6)}$ for five minutes and then $20 \%$ normal swine serum in TBS for 20 minutes. The three stage immunoperoxidase technique was then performed to identify the type of mononuclear cell infiltrate within the sections. Briefly, sections were incubated with optimally diluted primary antibody overnight (Table II)

TABLE II Primary antibodies used in three stage immunoperoxidase technique

\begin{tabular}{|c|c|c|c|}
\hline Antibody & Reactivity & Source & Dilution \\
\hline $\begin{array}{l}\text { Monoclonal } \\
2811+\text { PD } 7 / 26\end{array}$ & $\begin{array}{l}\text { Strong; lymphocytes variable; } \\
\text { macrophages }\end{array}$ & Dakopatts & $1: 100$ \\
\hline Monoclonal L26 & Strong; B cells & Dakopatts & $1: 100$ \\
\hline Monoclonal UCHL1 & $\begin{array}{l}\text { Strong; activated T cells; some resting T } \\
\text { cells }\end{array}$ & Dakopatts & $1: 100$ \\
\hline Polyclonal muramidase & Strong; monocytes/macrophages & Dakopatts & $1: 400$ \\
\hline
\end{tabular}

TABLE III Histological features of gall bladders in primary sclerosing cholangitis (PSC) and chronic cholecystitis (CC)

\begin{tabular}{|c|c|c|c|c|c|c|c|c|c|c|c|c|}
\hline \multirow[b]{2}{*}{ Histological features } & \multicolumn{6}{|c|}{ Patients with PSC } & \multicolumn{6}{|c|}{ Patients with CC } \\
\hline & 1 & 2 & 3 & 4 & 5 & 6 & 1 & 2 & 3 & 4 & 5 & 6 \\
\hline \multicolumn{13}{|l|}{ Epithelium } \\
\hline Papillary hyperplasia ${ }^{\star}$ & 1 & 1 & 2 & 1 & 0 & 1 & 1 & 0 & 0 & 1 & 2 & 0 \\
\hline Pseudoglands & 1 & 1 & 1 & 1 & 1. & $\mathrm{i}$ & 0 & 0 & 0 & 2 & 2 & 2 \\
\hline Mononuclear cell infiltrate† & + & & + & + & + & + & + & + & - & + & + & - \\
\hline \multicolumn{13}{|l|}{ Inflammation } \\
\hline Severity & 1 & 3 & 1 & 2 & 2 & 2 & 2 & 2 & 1 & 1 & 2 & 1 \\
\hline Siteł & $S+D$ & & $\dot{S}$ & $\mathrm{~S}$ & $\mathrm{~S}$ & $\tilde{s}$ & 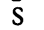 & $\hat{S}$ & D & $\dot{s}$ & D & $S+D$ \\
\hline Follicles & - & + & - & + & + & + & + & - & - & - & - & - \\
\hline Smooth muscle hypertrophy & 1 & 0 & 1 & 1 & 1 & 1 & 2 & 1 & 1 & 1 & 2 & 1 \\
\hline \multicolumn{13}{|l|}{ Fibrosis } \\
\hline Severity & 1 & 3 & 1 & 2 & 2 & 2 & 1 & 2 & 3 & 2 & 1 & 1 \\
\hline Site & $S+D$ & D & D & D & D & D & D & $S+D$ & D & $\hat{S}$ & D & D \\
\hline
\end{tabular}

${ }^{\star} 0=$ absent, $1=$ mild, $2=$ moderate, $3=$ severe.

$\dagger+=$ present,$-=$ absent .

$\neq S=$ predominantly superficial, $D=$ predominantly deep. and washed in two changes of TBS for five minutes. Rabbit anti-mouse peroxidase conjugated antibodies (Dakopatts) diluted $1 / 30$ in TBS were added for 45 minutes, after which the sections were washed in TBS and then incubated with swine anti-rabbit peroxidase conjugated antibodies (Dakopatts) diluted 1/30 in TBS for a further 45 minutes. After washing in TBS the sections were covered with fresh diaminobenzidine (DAB) substrate $(6 \mathrm{mg}$ DAB in $10 \mathrm{ml}$ TBS with $10 \mu \mathrm{l}$ of $30 \% \mathrm{H}_{2} \mathrm{O}_{2}$ ) for eight minutes, washed in TBS, counter stained with haematoxylin, dehydrated, and mounted. Control lymph node sections and sections without primary antibody were included in each assay run.

\section{EXAMINATION OF SECTIONS}

Routine haematoxylin and eosin stained sections were reviewed blindly by two of us (KBS, GPJ). The presence, site, and severity (grade 0 to 3 ) of the following histological features were noted: biliary epithelial abnormalities (hyperplasia, pseudoglands, mononuclear cell infiltrate); inflammatory cell infiltrate (mononuclear cells, polymorphs); smooth muscle hypertrophy; fibrosis; vasculitis; and granuloma. The immunoperoxidase sections were also viewed blindly and the site, cell type, and severity of the mononuclear cell infiltrate in each gall bladder was estimated and graded using a scale from 0 to 3 ( 0 =absent, $1=$ mild, $2=$ moderate, $3=$ severe) . A semiquantitative method was used to estimate the number of labelled cells that infiltrated the biliary epithelium. The number of infiltrating labelled cells in two high power fields was counted and the mean cell number calculated. Those two areas of biliary epithelium that were most severely affected by the inflammatory cell infiltrate were chosen for each section.

STATISTICS

Statistical analysis was performed using the Mann-Whitney $U$ test (two tailed) and $\chi^{2}$ with Yates's correction.

\section{Results}

The histological features present in the haematoxylin and eosin stained sections of gall blad- 


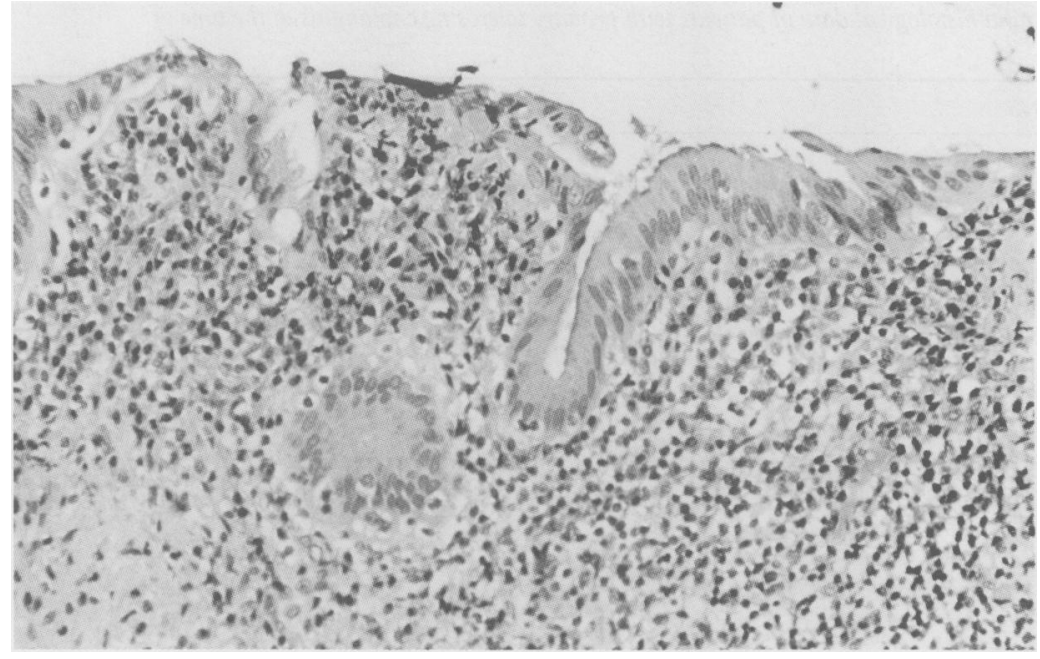

Figure 1: Haematoxylin and eosin staining of a primary sclerosing cholangitis gall bladder showing a dense mononuclear cell infiltrate in the superficial layers. (Original magnification $\times 250$.)

ders from patients with primary sclerosing cholangitis compared with those from patients with chronic cholecystitis are found in Table III. No distinguishing features characteristic of primary sclerosing cholangitis were identified. Epithelial changes of papillary hyperplasia and pseudogland formation were present in both disorders. Although mononuclear cell infiltration of the epithelium was present more fre-

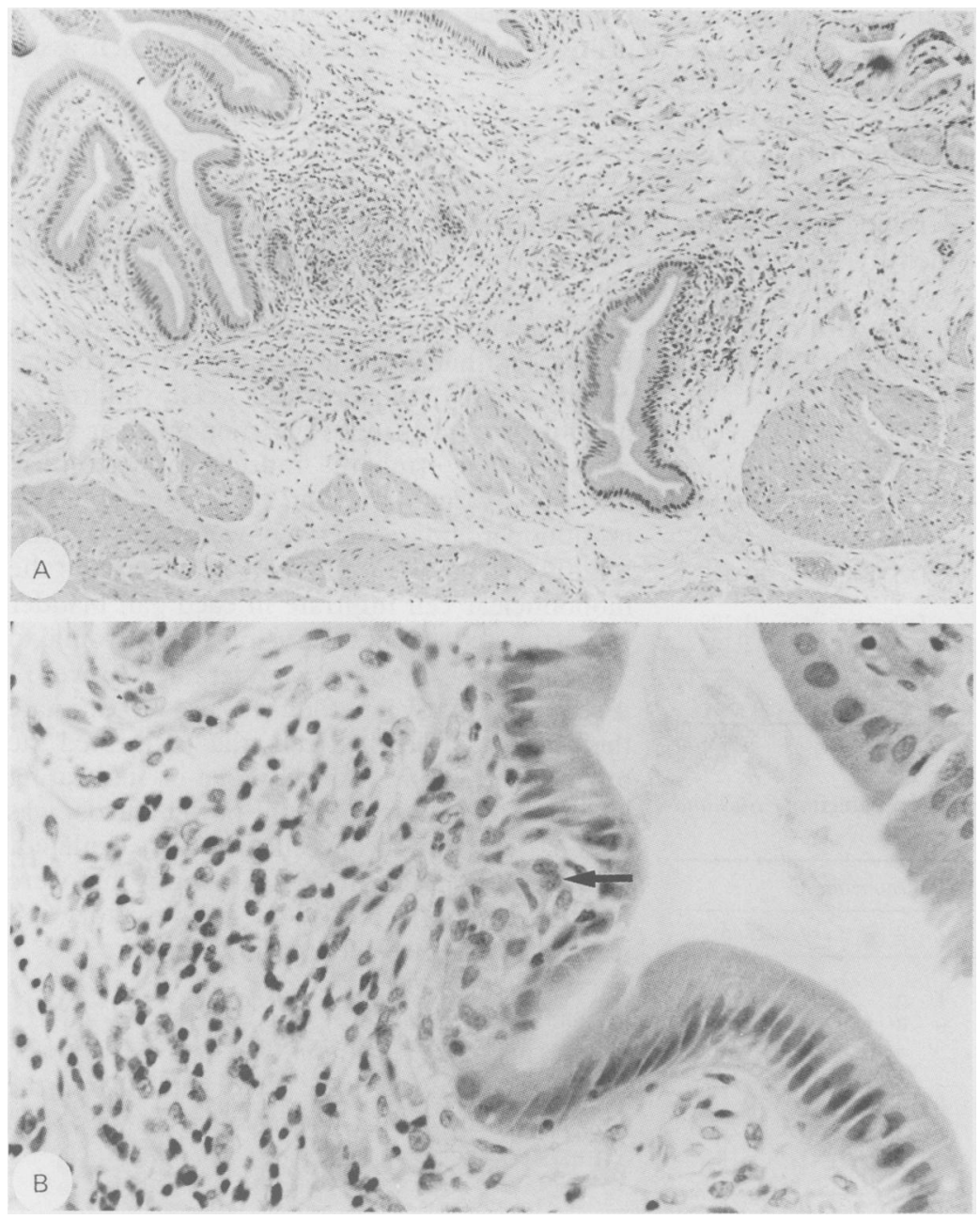

Figure 2: Haematoxylin and eosin staining of a primary biliary cirrhosis gall bladder showing: $(A)$ superficial granulomas. (Original magnification $\times 100$.) (B) Granuloma involving the biliary epithelium. The arrow shows an epithelioid histiocyte. (Original magnification $\times 400$.) quently in primary sclerosing cholangitis, it was also found in chronic cholecystitis. The site and severity of inflammation within the gall bladder wall was also similar in both disorders, although follicles were present more often in primary sclerosing cholangitis. However, the difference was not significant $(p>0 \cdot 1)$. The cell infiltrate in primary sclerosing cholangitis gall bladders was predominantly mononuclear cells with occasional polymorphonuclear cells (Fig 1). Smooth muscle hypertrophy and fibrosis were also present to the same degree in primary sclerosing cholangitis and chronic cholecystitis gall bladders. The presence and severity of histological abnormalities in primary sclerosing cholangitis gall bladders did not correlate with the presence of extrahepatic cholangiographic abnormalities. Vasculitis and granulomas were not found in these gall bladders. A similar range of histological features was present in the four primary biliary cirrhosis gall bladders, although in one, multiple epithelioid granulomas were present in the superficial layers and affected the biliary epithelium (Fig 2).

Immunohistochemical staining of gall bladders from patients with primary sclerosing cholangitis showed that the inflammatory cell infiltrate was composed predominantly of lymphocytes (Table IV). Most of these cells were T lymphocytes (active and resting), while $B$ lymphocytes were present only in lymphoid follicles (Fig 3). Comparative studies using liver biopsy specimens from three primary sclerosing cholangitis patients found a similar T lymphocyte infiltrate in portal tracts. In contrast, macrophages were found in equal or greater numbers than lymphocytes in the inflammatory cell infiltrate in chronic cholecystitis gall bladders. Gall bladders from patients with primary biliary cirrhosis had less severe inflammation than those from patients with primary sclerosing cholangitis, although lymphocytes were the predominant cell type. All four liver biopsy specimens from patients with primary biliary cirrhosis had a $T$ lymphocyte infiltrate within the portal tracts which was similar to the findings in primary sclerosing cholangitis.

T lymphocytes were frequently found infiltrating the biliary epithelium of primary sclerosing cholangitis gall bladders, whereas B lymphocytes and macrophages were not present. $T$ lymphocytes were apposed to the base and interdigitated between the epithelial cells (Fig 4). The number of T lymphocytes per high power field infiltrating the biliary epithelium in primary sclerosing cholangitis gall bladders (mean 21.5 ) was significantly more than in chronic cholecystitis gall bladders (mean $1.2 ; p<0.01$ ) (Fig 5). Primary biliary cirrhosis gall bladders also had fewer $\mathrm{T}$ lymphocytes per high power field infiltrating the biliary epithelium (mean 6 ), but the difference was outside the range of significance $(p=0.052)$. This result was due mainly to the primary biliary cirrhosis patient with multiple superficial granulomas who had a mean of $14 \mathrm{~T}$ lymphocytes per high power field.

\section{Discussion}

Gall bladder involvement in primary sclerosing 
TABLE IV Immunohistochemical typing of gall bladder mononuclear cell infiltrate

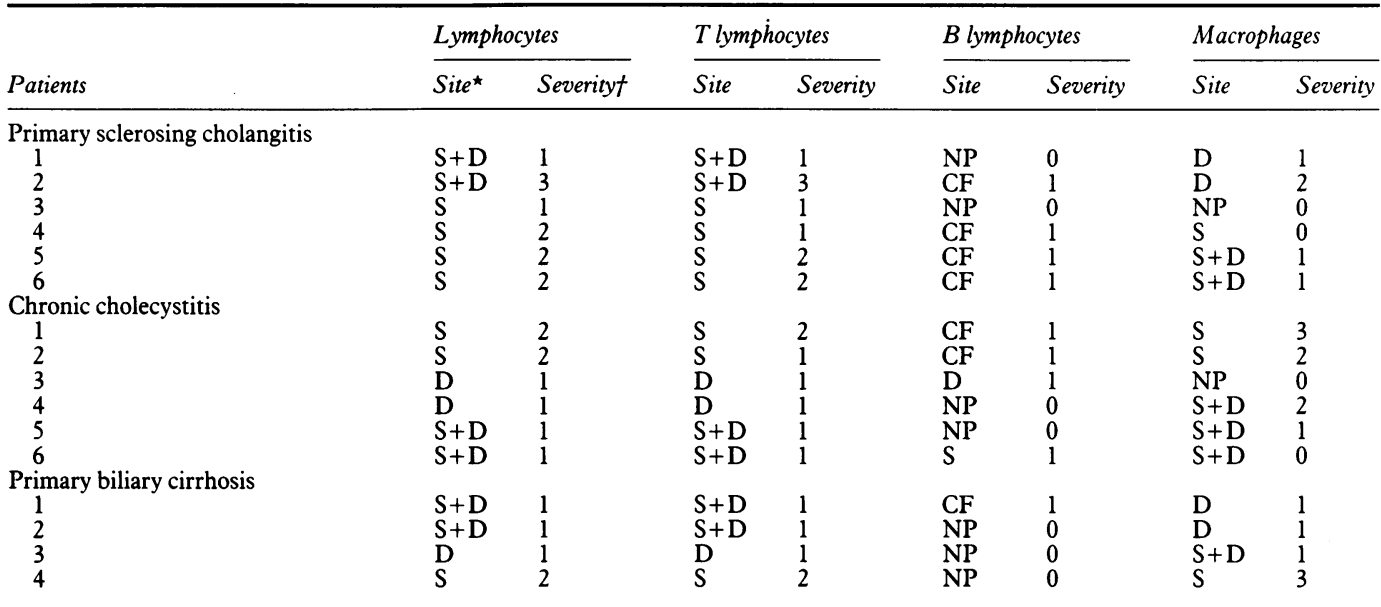

$\star S=$ predominantly superficial, $\mathrm{D}=$ predominantly deep, $\mathrm{CF}=$ centre of follicle, $\mathrm{NP}=$ not present

$\dagger 0=$ absent, $1=$ mild, $2=$ moderate, $3=$ severe.

cholangitis has been recognised since the first reports of this disorder were published, ${ }^{14}$ but few detailed histological studies have been performed. An early study of gall bladders in primary sclerosing cholangitis found that the striking feature of this lesion was the presence of lymphoid aggregates and abundant plasma cells within the lamina propria. $^{15}$ A case report described the presence of mucosal ulceration,

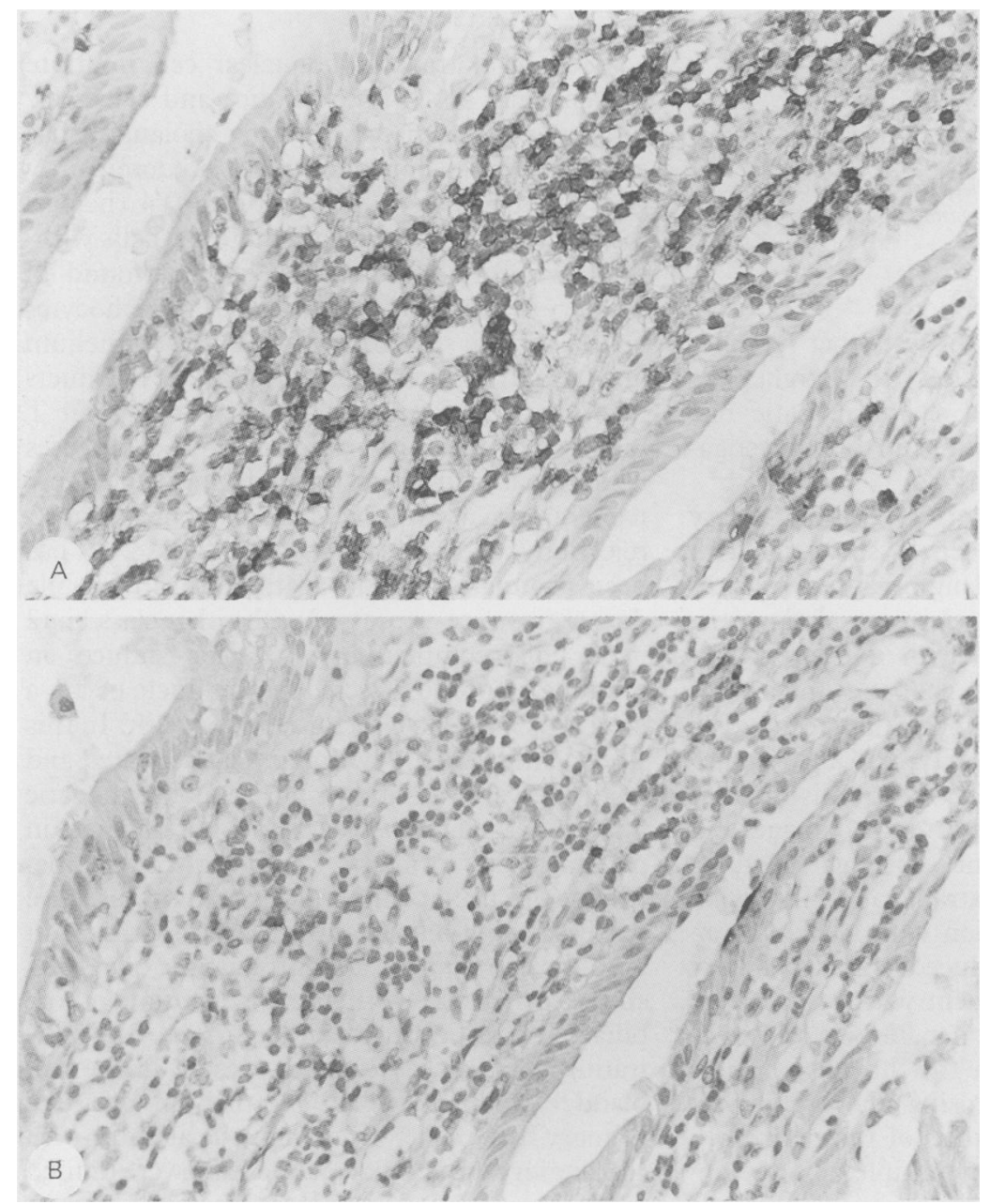

Figure 3: Immunoperoxidase staining of a primary sclerosing cholangitis gall bladder showing a predominant $T$ lymphocyte mononuclear cell infiltrate: $(A)$ Positive T lymphocyte staining using UCHL1. (B) Negative B lymphocyte staining using L26. (Original magnification $\times 400$.) granulomatous inflammation, and fibrosis within the gall bladder wall, ${ }^{16}$ and another found elongated mucosal papillary folds, pseudoglandular invaginations, and noticeable chronic inflammatory fibrosis, principally involving the serosa. ${ }^{17} \mathrm{~A}$ more recent study of gall bladder disease in primary sclerosing cholangitis patients found that $26 \%$ had gall stones, $15 \%$ had probable primary sclerosing cholangitis affecting the gall bladder, and $4 \%$ had neoplasms (benign and malignant). ${ }^{18}$ Detailed histological features were not reported, however, and no pathognomonic features of the disease were identified.

Only one of the six primary sclerosing cholangitis patients in this study had ulcerative colitis, although asymptomatic disease may have been present in one other patient who refused fibreoptic sigmoidoscopy. This finding is not representative of the proportion of patients with ulcerative colitis in the total primary sclerosing cholangitis population, which was $58 \%$. As a consequence, those patients without ulcerative colitis included in this study may be somewhat atypical, although the ulcerative colitis in this disorder is usually only mildly symptomatic and has prolonged periods of remission. ${ }^{2}$ In this study no histological abnormality present in routine haematoxylin and eosin stained sections of primary sclerosing cholangitis gall bladders was identified as being specific for this disorder. The severity and type of inflammation, fibrosis, smooth muscle hypertrophy, and epithelial abnormalities in primary sclerosing cholangitis were similar to those present in chronic cholecystitis and primary biliary cirrhosis. The presence of lymphoid follicles associated with moderately severe chronic inflammation was the only feature that tended to occur more frequently in primary sclerosing cholangitis gall bladders, similar to the findings of Thorpe et al..$^{15}$ Granulomatous inflammation was not present in any primary sclerosing cholangitis gall bladder in contrast with a previous report. ${ }^{16}$ One primary biliary cirrhosis gall bladder, however, had multiple granuloma within the submucosa and epithelial cell layer. Extrahepatic granuloma in this disease have previously been reported in liver hilar lymph nodes, omentum, and lung. ${ }^{19}$ The presence of gall bladder granulomas in 


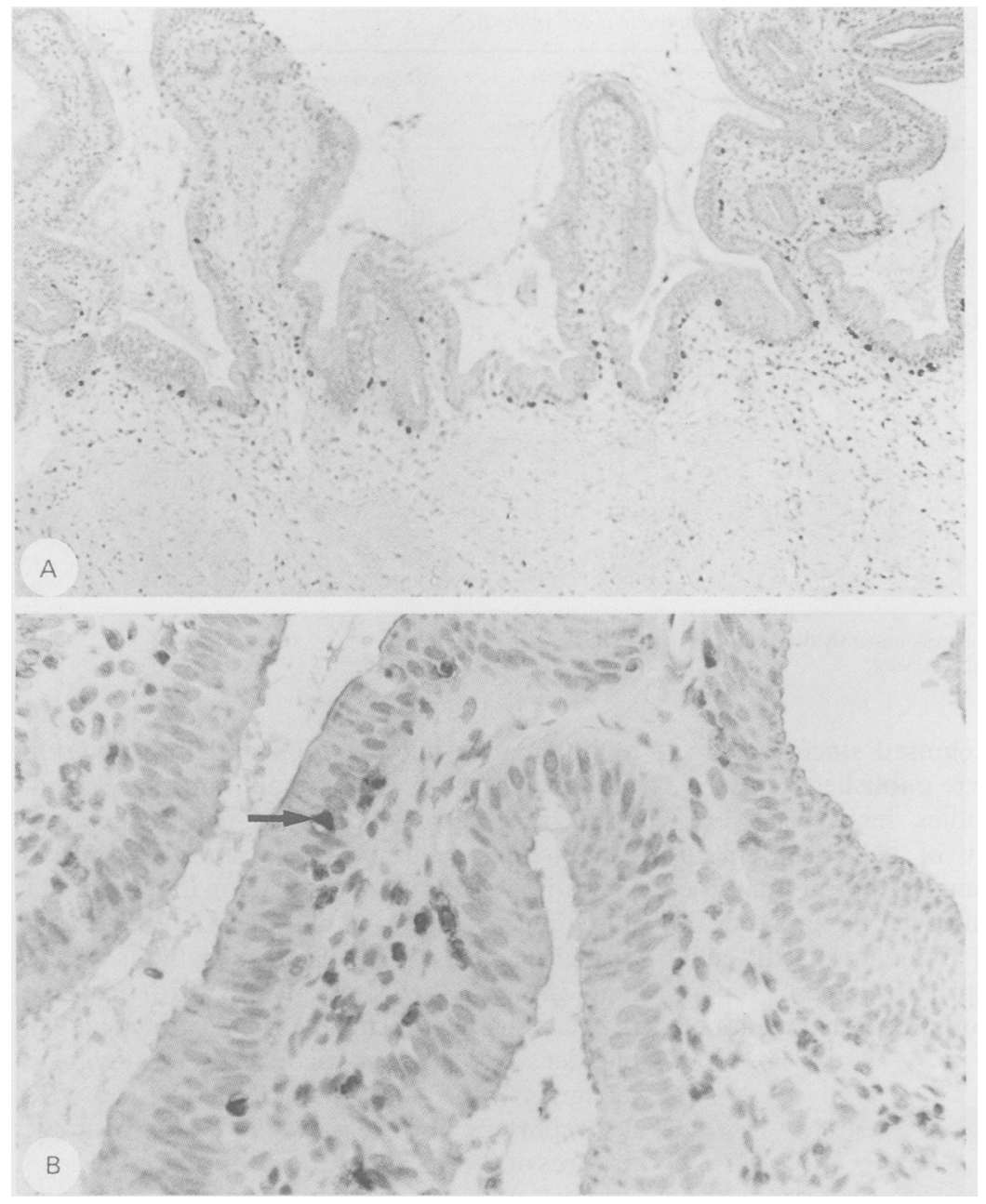

Figure 4: Immunoperoxidase staining of a primary sclerosing cholangitis gall bladder showing positive staining of $T$ lymphocytes: $(A)$ Numerous $T$ lymphocytes apposed to the base of biliary epithelial cells. (Original magnification $\times 100$.) $(B)$ High power field of $T$ lymphocytes infiltrating the biliary epithelium. The arrow shows a Tlymphocyte interdigitating between epithelial cells. (Original magnification $\times 400$.) primary biliary cirrhosis suggests that lymphocytes may also be sensitised to extrahepatic biliary epithelium as well as intrahepatic bile ducts and this finding requires further investigation.

Damage to the hepatic artery and peribiliary vascular plexus has been associated with the development of cholangiographic features characteristic of primary sclerosing cholangitis. Hepatic artery infusion with 5-fluorodeoxyuridine in patients with hepatic metastases from colorectal adenocarcinoma has resulted in multiple biliary strictures typical of primary sclerosing cholangitis. ${ }^{20}$ The infusion is thought to produce toxic hepatic arterial damage and narrowing which results in ischaemic strictures of the intrahepatic and extrahepatic bile ducts. Hepatic artery embolisation with alcohol in an animal model has produced similar biliary lesions. ${ }^{21}$ Moreover, a patient with polyarteritis nodosa that affected the hepatic artery extensively was reported to have the cholangiographic features of primary sclerosing cholangitis. ${ }^{22}$ It was postulated that vasculitis of the peribiliary vascular plexus resulted in multiple biliary strictures and dilatations. Severe occlusive phlebitis has also been described in a primary sclerosing cholangitis gall bladder. ${ }^{17}$ This lesion was thought to be a specific feature of the disease and

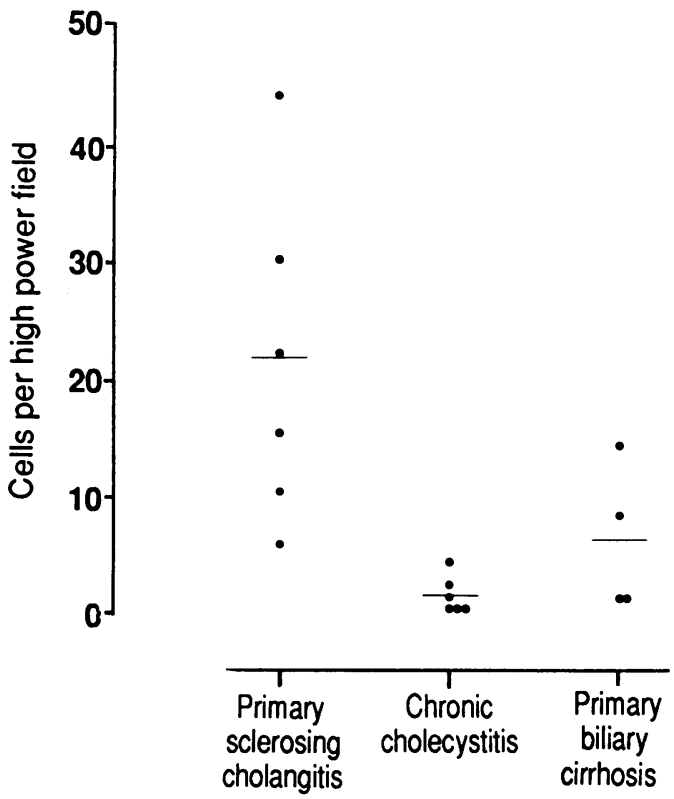

Figure 5: The number of T lymphocytes per high power field infiltrating the biliary epithelium in primary sclerosing cholangitis, chronic cholecystitis, and primary biliary cirrhosis gall bladders. _ indicates mean number.

was implicated in its pathogenesis. Vasculitis was not found in any primary sclerosing cholangitis gall bladder in the present study, however, and this suggests that while hepatic artery damage may produce secondary ischaemic biliary strictures, it is unlikely to play a role in the pathogenesis of the disorder.

The portal tract mononuclear cell infiltrate present in both precirrhotic and cirrhotic patients with primary sclerosing cholangitis has previously been shown to consist predominantly of T lymphocytes. ${ }^{923}$ The ratio of T4 (helper/ inducer) to T8 (suppressor/cytotoxic) cells within this infiltrate was similar to that found in primary biliary cirrhosis patients. T lymphocytes have also been shown to infiltrate the epithelium of large and medium sized intrahepatic bile ducts in primary sclerosing cholangitis. ${ }^{2923}$ Similar T lymphocyte infiltration occurs in other diseases which result in the vanishing bile duct syndrome; namely primary biliary cirrhosis, ${ }^{24}$ chronic graft rejection, ${ }^{25}$ and grafts versus host disease.$^{26}$ It has been postulated that in all these disorders bile duct antigens co-expressed with either class 1 or 2 major histocompatibility antigens induce an immune response directed at bile ducts or are a target for immune effector cells, or both. In this study, infiltrating T lymphocytes (activated and resting) were found within the extrahepatic biliary epithelium as well as the portal tracts in patients with primary sclerosing cholangitis. This suggests that lymphocytes in this disease are sensitised to a biliary antigen that is present in both the extrahepatic and intrahepatic bile ducts and is consistent with the distribution of the biliary lesions in this disorder. Moreover, infiltrating $\mathrm{T}$ lymphocytes were present in the gall bladder wall and biliary epithelium of three primary sclerosing cholangitis patients with cholangiographic abnormalities that were limited to the intrahepatic biliary tree. This also suggests that cholangiography may not always detect the presence of extrahepatic disease, especially if the extrahepatic lesion consists predominantly of 
inflammatory changes without any appreciable fibrosis and stricturing.

In conclusion, this study has shown that a wide range of non-specific histological features of chronic inflammation and fibrosis were present in routine haematoxylin and eosin stained sections of primary sclerosing cholangitis gall bladders. Immunohistochemistry found other features that were present in the disease, and these consisted of a lymphocytic mononuclear cell infiltrate that affected all layers of the gall bladder wall and the presence of T lymphocytes (activated and resting) which infiltrated the biliary epithelium. These findings support the hypothesis that lymphocytes in primary sclerosing cholangitis are sensitised to a biliary antigen and may play a role in the pathogenesis of both the intrahepatic and extrahepatic lesions in this disorder. Further studies investigating $T$ lymphocyte subtypes and biliary epithelial expression of class 1 and 2 major histocompatibility antigens in optimally fixed primary sclerosing cholangitis gall bladders are planned.

Gary Jeffrey holds a NH\&MRC Medical Postgraduate Research Scholarship and the study was supported by a grant from the Si Charles Gairdner Hospital Research Foundation. We thank Fran Geste for typing the manuscript.

1 Sherlock S. The syndrome of disappearing intrahepatic bile ducts. Lancet 1987; ii: 493-6.

2 Chapman RW, Marborgh BA, Rhodes JM, et al. Primary sclerosing cholangitis: a review of its clinical features, cholangiography and hepatic histology. Gut 1980; 21 : 870-7.

3 Jeffrey GP, Reed WD, Laurence BH, Shilkin KB. Primary sclerosing cholangitis - a clinical and immunopathological review of 21 cases. F Gastroenterol Hepatol 1990; 5: 135-40.

4 Bodenheimer HC, LaRusso NF, Thayer WR, Charland C, Staples P, Ludwig J. Elevated circulating immune complexes in primary sclerosing cholangitis. Hepatology 1983; 3: plexes in $150-4$.

5 Alberti-Flor JJ, Medina M, Jeffers L, Schultz DR, Schiff ER. Elevated levels of immunoglobulins and immune complexe in the bile of patients with primary sclerosing cholangitis Am F Gastroenterol 1986; 81: 325-8.

6 Brinch L, Triesberg P, Schrumpf E, Akesson I. The in vivo metabolism of $\mathrm{C} 3$ in hepatobiliary disease associated with ulcerative colitis. Scand $\mathcal{F}$ Gastroenterol 1982; 17: 523-7.
7 Minuk GY, Angus M, Brickman CM, et al. Abnormal clearance of immune complexes from the circulation of patients with primary sclerosing cholangitis. Gastroenterology 1985; 88: 166-70.

8 MacFarlane IG, Wojcicka BM, Tsantoulas DC, Portmann BL, Eddleston ALWF, Williams R. Leukocyte migration inhibition in response to biliary antigens in primary biliary tion in response to biliary antigens in primary biliary
cirrhosis, sclerosing cholangitis and other chronic liver cirrhosis, sclerosing cholangitis and other
diseases. Gastroenterology 1979; 76: 1333-40.

9 Whiteside TL, Lasky S, Si L, Van Thiel DH. Immunological analysis of mononuclear cells in liver tissue and blood of patients with primary sclerosing cholangitis. Hepatology 1985; 5: 468-74.

10 Magrin S, Nouri-Aria KT, Donaldson PT, et al. The relationship between HLA-DR3 and T-cell regulation of immunoglobulin production in primary sclerosing cholangitis. Clin Immunol Immunopathol 1989; 50: 205-12.

11 Chapman RW, Kelly PMA, Heryet A, Jewell DP, Fleming KA. Expression of HLA-DR antigens on bile duct epitheKA. Expression of HLA-DR antigens on bile duct epithe-
lium in primary sclerosing cholangitis. Gut $1988 ; 29: 422-7$.

12 Ludwig J, MacCarty RL, LaRusso NF, Krom RAF, Wiesner RH. Intrahepatic cholangiectasis and large duct obstruction RH. Intrahepatic cholangiectasis and large duct obstruction
in primary sclerosing cholangitis. Hepatology $1986 ; 6: 560-8$. 13 LaRusso NF, Wiesner RH, Ludwig J, MacCarty RL. Primary sclerosing cholangitis. N Engl f Med 1984; 310: 899-903. 14 Schwartz SI, Dale WA. Primary sclerosing cholangitis. Review and report of six cases. Arch Surg 1958; 77: 439-50.

15 Thorpe MEC, Scheuer PJ, Sherlock S. Primary sclerosing cholangitis, the biliary tree and ulcerative colitis. Gut 1967; 8: $435-48$.

16 Goldgraber MB, Kirsner JB. Chronic granulomatous cholecystitis and chronic fibrosing choledochitis associated with cystitis and chronic fibrosing choledochitis associated with
chronic ulcerative colitis. A case report. Gastroenterology chronic ulcerative

$1960 ; 38: 821-8$.
17 Case records of the Massachusetts General Hospital. N Engl F Med 1982; 306: 349-58.

18 Brandt DJ, MacCarty RL, Charboneau JW, LaRusso NF, Wiesner RH, Ludwig J. Gallbladder disease in patients with primary sclerosing cholangitis. $A \mathcal{F} R$ 1988; 150: $571-4$.

19 Fox RA, James DG, Scheuer PJ, Sharma O, Sherlock S. Impaired delayed hypersensitivity in primary biliary cirrhosis. Lancet 1969; i: 959-62.

20 Kemeny MM, Battifora H, Blayney DM, et al. Sclerosing cholangitis after continuous hepatic artery infusions of FUDR. Ann Surg 1985; 202: 176-81.

21 Doppman JL, Girton ME. Bile duct scarring following ethanol embolization of the hepatic artery. An experimental study in monkeys. Radiology 1984; 152: 621-6.

22 Doppman JL, Dunnick NR, Girton M, Fauci AS, Popovsky MA. Bile duct cysts secondary to liver infarcts: Report of a case and experimental production by small vessel hepatic artery occlusion. Radiology 1979; 130: 1-5.

23 Snook JA, Chapman RW, Sachdev GK, et al. Peripheral blood and portal tract lymphocyte populations in primary sclerosing cholangitis. F Hepatol 1989; 9: 36-41.

24 Scheuer PJ. Liver biopsy interpretation. 3rd ed. London: Baillière Tindall, 1980: 36-59.

25 Vierling JM, Fennell RH. Histopathology of early and late human hepatic allograft rejection: evidence of progressive human hepatic allograft rejection: evidence of progressive
destruction of interlobular bile ducts. Hepatology 1985; 5: destructio

26 Shulman HM, Sharma P, Amos D, Fenster LF, McDonald GB. A coded histologic study of hepatic graft-versus-host disease after human bone marrow transplantation. Hepatology 1988; 8: 463-70. 